\title{
Analysis of Bottom Frame Structure on Seismic Performance
}

\author{
Hongyu Deng* \\ College of Space Technology and Civil Engineering \\ Harbin Engineering University \\ Harbin, China \\ E-mail: dengblue@163.com \\ * Corresponding Author
}

\begin{abstract}
In order to study the seismic performance of masonry buildings with frame and seismic-wall in the lower stories, a serious damaged bottom frame structure in Wenchuan earthquake was taken as the research object in this paper. The eccentricity of each layer of the structure was calculated, and seismic damage prediction method was used to judge the weak floor of structure. Elastic time- history analysis and numerical simulation were carried out on the use of ABAQUS finite element software. Calculation results show that: at the bottom layer of the structure with excess reinforced concrete anti-seismic wall and filled wall, the stiffness and the resistance is greatly increased, and that makes the weak floor of the structure transfers from the bottom layer with better ductility and energy dissipation to the second layer of masonry floor. Also under the horizontal earthquake action, the whole structure especially the first floor has obvious torsional coupling response, also increases the damage of the second layer, eventually leading to the destruction of the whole structure.
\end{abstract}

Keywords-Bottom Frame Structure; Seismic Capacity; Eccentricity; Torsion; Elastic Time-history Analysis

\section{INTRODUCTION}

Masonry buildings with frame and seismic-wall in the lower stories refers to hybrid bearing buildings which the bottom or the bottom two layers are shear walls, and the upper part is Multistory masonry structure. In our country, this kind of buildings is widely used in street buildings. Considering the economic development of our country, bottom frame structure in our country is widely used and will exist for a long time, so it is of great practical significance to study the failure mechanism of the bottom frame structure and to improve the seismic capability of the bottom frame structure[1]. In this paper, a serious damaged bottom frame structure in Wenchuan earthquake was taken as the research object, and elastic time-history analysis and numerical simulation were carried out on the use of ABAQUS finite element software. The calculation results show that: under the earthquake action, the structure produced significant torsional response which is one of the main reasons for the serious damage of the structure. And the analysis to the causes of torsion is carried on and design recommendations are given.

\author{
Baitao Sun \\ Earthquake Administration \\ Key Laboratory of Earthquake Engineering and \\ Engineering Vibration of China Earthquake \\ Administration \\ Harbin, China
}

\section{BRIEF INTRODUCTION OF DAMAGE}

\section{A. Engineering situation}

This bottom frame structure is located in Mianzhu City of Sichuan province, the total number of layers is six layers. The height of the bottom story is $3.8 \mathrm{~m}$; and the second to the sixth layer is $3 \mathrm{~m}$. The structure was built in 2001. In this project, MU10 red bricks are used and mortar strength of the first layer is M5 mixed mortar, the second layer M7.5 mixed mortar, the third layer M5 mixed mortar. The frame and floor of the bottom story is C30, the ring beam, structural column, precast floor slab of other layers adopts C20 concrete. Structural stirrups use HPB235, longitudinal bearing force reinforcement uses HRB335. The first building floor plan (Fig .1) and the standard floor plan (Fig .2) are shown in below.

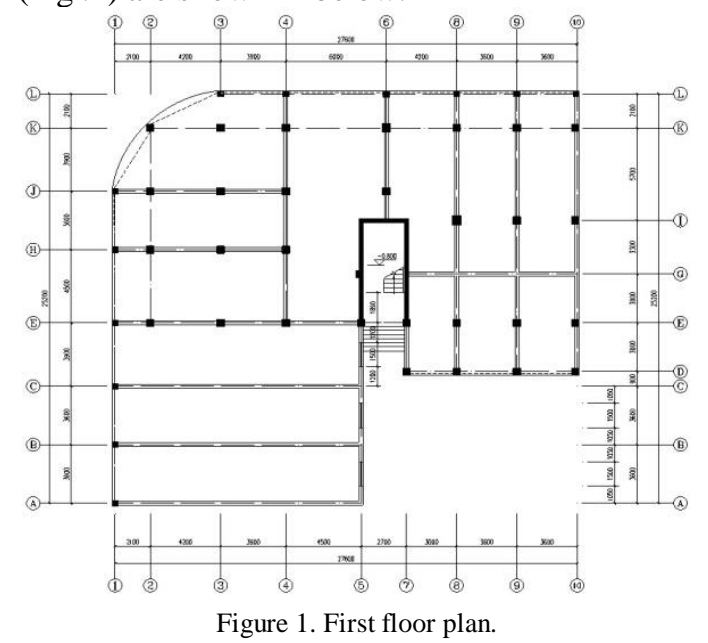

Figure 1. First floor plan. 


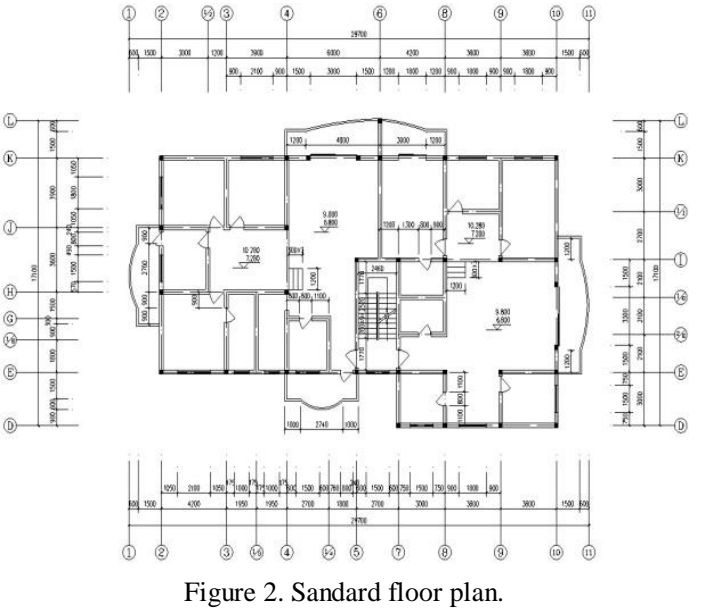

\section{B. Damage of the Structure}

In Wenchuan earthquake, the distance between Mianzhu City and the epicenter of Yingxiu Town, which was only $150 \mathrm{~km}$. Mianzhu City located in the northwest of fracture zone of Longmen Mountain, and the intensity of this city was VIII, IX and X degree[2] from the southeast to the northwest in order(Fig .3). According to the latitude and longitude of The No.4 Tianhexinyuan building, it could be determined that the structure located in the edge of IX degree.

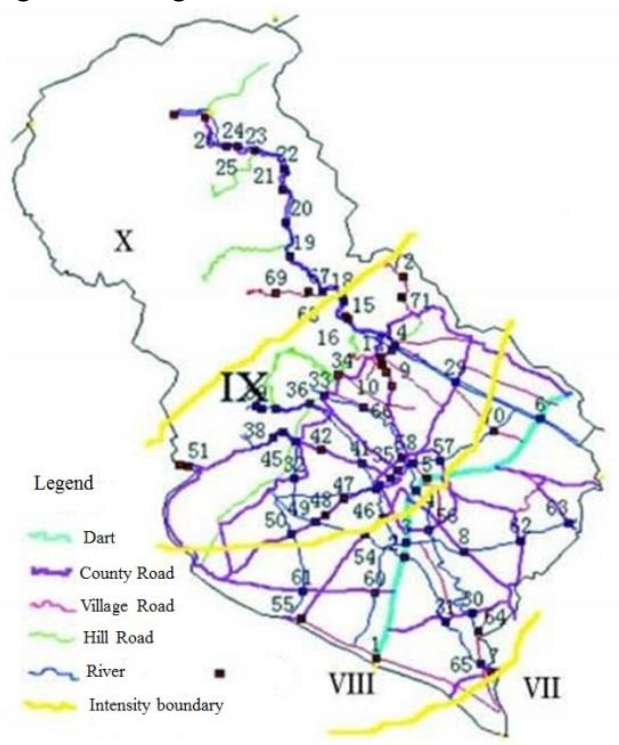

Figure 3. Intensity distribution of Mianzhu City in Wenchuan earthquake.

The damage situation of this project included: the infill of bottom frame had multiple cracking, the frame column, beam and concrete shear walls were slightly damaged, most load-bearing walls of transitional masonry had oblique throughout cracks, and walls near to the door corner cracked in diagonal, X type crack appeared in the wall under windows. Earthquake damage level of this structure was serious damage. The damage situation of the structure was shown in Fig .4.

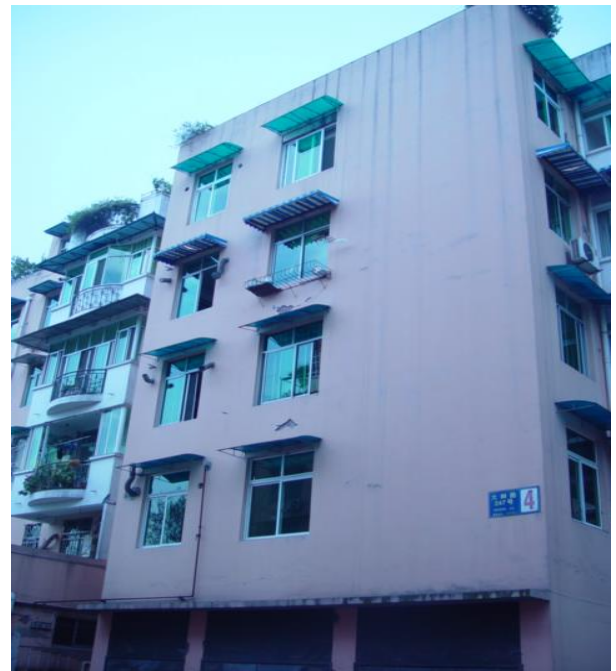

(a). Damage of the overall structure.

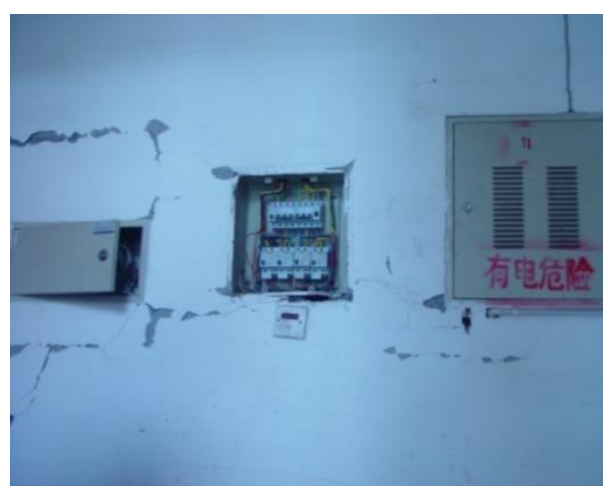

(b). Damage of the staircase.

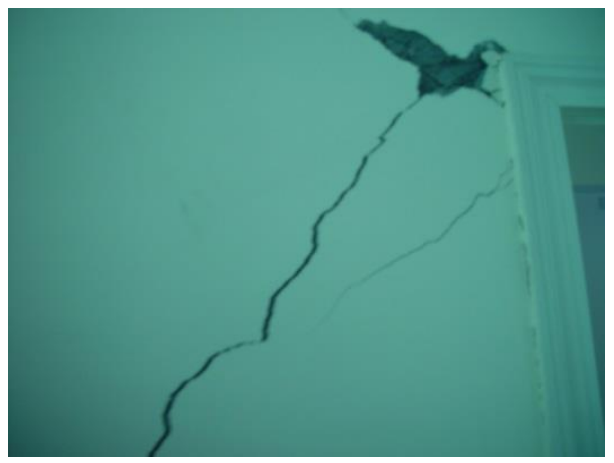

(c). Wall damage in the corner of a door.

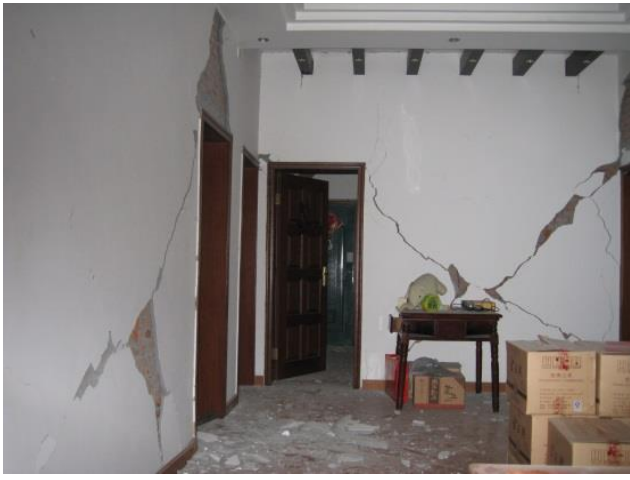

(d). Damage in transitional masonry.

Figure 4. Damage situation of the structure. 


\section{STYLINGSTRUCTURAL DESIGN ANALYSIS AND DISCRIMINANT OF WEAK FLOOR}

\section{A. Checking calculation of ratio of lateral stiffness}

Masonry buildings with frame and seismic-wall in the lower stories are composed of frame and masonry, which is a hybrid structural system. Due to the different forms of structure, a great difference is caused between the interstory drift stiffness of the floor layers. Especially then transition layer will produce an abrupt change in stiffness, resulting in stress concentration that makes the masonry storey serious destruction. Therefore Therefore, in China, the specification[3] of masonry buildings with frame and seismic-wall in the lower stories stipulate that in both horizontal and longitudinal directions, the lateral stiffness ratio of the second layer included the effect of constructional column of the lateral stiffness and the bottom layer, sixth and seventh degrees should not be greater than 2.5, eighth degree should not greater than 2.0 and shall not be less than 1.0. The ratio of lateral stiffness is checked according to the construction drawings. The relevant calculation formulas are from the literature [4] appendix A. The lateral force-resisting members of the first layer include frame columns, frame beams, reinforced concrete anti-seismic walls and masonry podium. Twostory masonry layer does not distinguish between the size of openings, and all the door and window openings are divided into wall segments. The influence of constructional column is considered to calculate the stiffness. The results of lateral stiffness ratio are shown in Table I.

TABLE I. RATIO OF LATERAL STIFFNESS

\begin{tabular}{|c|c|c|c|}
\hline $\begin{array}{c}\text { Direction of } \\
\text { structure }\end{array}$ & $\begin{array}{c}\text { Level lateral } \\
\text { rigidity of the } \\
\text { first floor } \\
\left(\times \mathbf{1 0}^{\mathbf{6}} \mathbf{~ k N} / \mathbf{m}\right)\end{array}$ & $\begin{array}{c}\text { Level lateral } \\
\text { rigidity of the } \\
\text { second floor } \\
\left(\times \mathbf{1 0}^{\mathbf{6}} \mathbf{~ k N / m}\right)\end{array}$ & $\begin{array}{c}\text { Ratio of } \\
\text { lateral } \\
\text { stiffness }\end{array}$ \\
\hline Lateral & 6.600 & 6.917 & 1.05 \\
\hline vertical & 3.380 & 5.648 & 1.67 \\
\hline
\end{tabular}

This project is designed according to 7 degree, so the calculation results of lateral stiffness ratio are satisfied with the value of 1.0 2.5. But during the process of calculating, the stiffness contributions of the infilled walls in the first layer are ignored. In the structural design of our country, the infilled wall is seen as a non-structural member, and its weight is simplified as linear load which effects at the beam. The infilled wall itself is not involved in seismic checking. This method of neglecting the contribution of the infilled wall stiffness is not always conservative. And the material of the infilled wall in this project is normal brick masonry, which has large dead weight and stiffness. Therefore, it is not suitable to neglect the infilled wall. According to the relevant formula of literature [4] in Appendix F, the ratio of lateral stiffness including the infilled wall stiffness is calculated, and the results are shown in Table II.
TABLE II. RATIO OF LATERAL STIFFNESS INCLUDING THE INFILLED WALL STIFFNESS

\begin{tabular}{|c|c|c|c|}
\hline $\begin{array}{c}\text { Direction of } \\
\text { structure }\end{array}$ & $\begin{array}{c}\text { Level lateral } \\
\text { rigidity of } \\
\text { the first floor } \\
\left(\times \mathbf{1 0}^{\mathbf{6}} \mathbf{~} \mathbf{N} / \mathbf{m}\right)\end{array}$ & $\begin{array}{c}\text { Level lateral } \\
\text { rigidity of the } \\
\text { second floor } \\
\left(\times \mathbf{1 0}^{\mathbf{6}} \mathbf{~ k N / m}\right)\end{array}$ & $\begin{array}{c}\text { Ratio of } \\
\text { lateral } \\
\text { stiffness }\end{array}$ \\
\hline Lateral & 7.042 & 6.917 & 0.98 \\
\hline vertical & 3.584 & 5.648 & 1.58 \\
\hline
\end{tabular}

The results show that: the ratio of lateral stiffness of the structure is less than 1.0 in horizontal direction when the infilled wall stiffness of the first layer is included. And the code requirement is not satisfied. Ratio of lateral stiffness is less than 1.0, which means too much reinforced concrete shear wall is set in the underlying structure which greatly increases the seismic capacity of the bottom floor. And that makes the weak floor of the structure transfers from the bottom layer with better ductility and energy dissipation to the second layer of masonry floor. It is also consentaneous compared with actual seismic damage of structure, that in the first layer of slight damage and the second floor of serious damage with load-bearing cross wall severe cracking. Therefore, structure design ignores the stiffness contribution of infilled walls completely sometimes produce erroneous results. And the ratio of lateral stiffness should also try to take the appropriate value, which is not too close with the specification limits.

\section{B. Calculation of Eccentricity}

Due to the irregular plane, the center of mass is not located in the plane at the center of the floor. And due to local large bay of a room, the stiffness distribution of floor is not uniform. Especially the stiffness of the first floor mainly is concentrated in the staircase of reinforced concrete shear wall, which leads to a larger eccentricity in the same floor between the center of mass and the center of stiffness. Under the horizontal earthquake action, the whole structure produces a torsion which aggravates the damage. The center of stiffness[5] refers to the stiffness distribution center of all lateral force-resisting members of the floor, and it is calculated according to the Equation (1). The center of mass[6] refers to the mass distribution center of all lateral force-resisting members of structure plane, and it is calculated according to the Equation (2).

$$
\begin{aligned}
& x_{s}=\frac{\sum K_{j} x_{j}}{\sum K_{j}}, y_{s}=\frac{\sum K_{k} y_{k}}{\sum K_{k}} \\
& x_{m}=\frac{\sum m_{j} x_{J}}{\sum m_{j}}, y_{m}=\frac{\sum m_{k} y_{K}}{\sum m_{k}}
\end{aligned}
$$

Where $\mathrm{xs}$ and ys are the coordinate of the center of stiffness, $\mathrm{Kj}$ and $\mathrm{Kk}$ is the lateral stiffness of $\mathrm{j}$ component and $\mathrm{k}$ component in the same floor, $\mathrm{xj}$ and $\mathrm{yk}$ are the coordinate of the center of stiffness of $\mathrm{j}$ component and $\mathrm{k}$ component, $\mathrm{mj}$ and $\mathrm{mk}$ are the mass of $\mathrm{j}$ component and $\mathrm{k}$ component in the same floor, $\mathrm{xJ}$ and $\mathrm{yK}$ are the coordinate of the center of mass of $\mathrm{j}$ component and $\mathrm{k}$ component. According to the formulas in above, the calculation results are shown in Table III. 
TABLE III. ECCENTRICITY OF EACH FLOOR OF STRUCTURE

\begin{tabular}{|c|c|c|}
\hline Floor & $\begin{array}{c}\text { Horizontal } \\
\text { eccentricity }(\mathbf{m})\end{array}$ & $\begin{array}{c}\text { Longitudinal } \\
\text { eccentricity }(\mathbf{m})\end{array}$ \\
\hline 1 & 6.24 & 2.22 \\
\hline 2 & 0.47 & 0.78 \\
\hline 3 & 0.32 & 0.85 \\
\hline 4 & 0.45 & 0.58 \\
\hline 5 & 0.43 & 0.4 \\
\hline 6 & 0.48 & 0.12 \\
\hline
\end{tabular}

According to the results, a larger eccentric exists in the longitudinal orientation of the second and third floor, and also in the horizontal orientation of the sixth floor. The eccentric of the first floor in both longitudinal and horizontal orientation reaches $2.22 \mathrm{~m}$ and $6.24 \mathrm{~m}$, which belongs to serious eccentric structure. Under the action of horizontal earthquake, the earthquake load of each floor are acted in the center of mass and rotated around the center of stiffness. The first floor has the maximum shear stress, and thus large eccentricity increases the torsion effect of the overall structure, which is one of the main reasons for the final destruction of the structure.

\section{Discriminant of weak floor in Structure}

According to the content of literature [4], the weak floor of this bottom frame structure can be predicated. Firstly, according to equivalent base shear to calculate the seismic shear value of each floor under rare earthquake of 7 degrees, then according to the related formulas in the literature [7]-[9], the shear capacity of reinforced concrete frame columns, seismic wall and common brick masonry wall can be calculated respectively, and the layer of ultimate shear bearing capacity of each floor will be found out. The ratio of storey bearing shear and the seismic shear in 7 degree rare earthquake elastic analysis for each layer is defined as yield strength coefficient, the results are shown in Table IV.

TABLE IV. STOREY YIELD STRENGTH COEFFICIENT

\begin{tabular}{|c|c|c|c|c|c|}
\hline \multirow{2}{*}{ Floor } & \multirow{2}{*}{$\begin{array}{c}\text { Seismic } \\
\text { shear } \\
\end{array}$} & \multicolumn{2}{|c|}{$\begin{array}{c}\text { Storey bearing } \\
\text { shear }(\mathbf{k N})\end{array}$} & \multicolumn{2}{c|}{$\begin{array}{c}\text { Storey yield } \\
\text { strength coefficient }\end{array}$} \\
\cline { 3 - 6 } & vertical & lateral & vertical & lateral \\
\hline 1 & 12200 & 14115 & 25133 & 1.16 & 2.06 \\
\hline 2 & 7807 & 3931 & 4735 & 0.50 & 0.61 \\
\hline 3 & 5987 & 3133 & 3803 & 0.52 & 0.64 \\
\hline 4 & 4168 & 2908 & 3456 & 0.70 & 0.83 \\
\hline 5 & 2356 & 2627 & 3074 & 1.12 & 1.30 \\
\hline 6 & 659 & 1543 & 2154 & 2.34 & 3.27 \\
\hline
\end{tabular}

It can be seen from the calculations, the minimum storey yield strength coefficient of upper masonry story is 0.5 in longitudinal direction and 0.61 in lateral direction, so it can be predicted that the second floor is the weak floor in structure. This result also consists with the actual damage which the second got heaviest damage. That means although the mortar strength of the second layer is increased from M5 to M7.5, but due to the second floor which compares to others has larger seismic shear, stiffness changes more violently, and is influenced by the first layer of the torsional response, it is still got heaviest damaged in the whole structure. The conclusion consists with the actual damage situation, which also validates the effectiveness and correctness of the proposed simplified method in literature [4] indirectly.

\section{ESTABLISHMENT OF FINITE ELEMENT MODEL}

The model was established through the finite element software ABAQUS, and finite element simulation was carried out of the prototype structure. Steel bar used surface unit (SF3D4R), floor and common brick masonry wall used shell unit (S4R), frame column, beam and reinforced concrete shear wall of the first layer used solid unit (C3D20R), infilled wall of the first layer was simplified as equivalent diagonal strut model, used the truss unit (T3D2). The tie connection in constraint was used between the floors and walls, join connection in the connector was used between the truss rod which simulated the infilled wall and used the truss unit (T3D2) and frame columns, the embedded connection was used between steel bars of frame columns, beams and steel reinforced concrete shear walls and the main part to simulate joint coordinating role of the steel and concrete, slab reinforcement was added to shell unit (S4R) which was used in the floor by using rebar in the pre CAE processing. The model was shown in Fig .5 (a).

\section{MODAL ANALYSIS}

Firstly, the model is calculated in modal, and calculates the torsional period ratio of structure. The method of modal calculation is using linear perturbation step of ABAQUS in implicit analysis module. This paper defines the longitudinal direction of structure as $X$ orientation and the lateral direction as $\mathrm{Y}$ orientation. Because the stiffness center does not coincide with the centroid in the structural plane, the existence of the eccentricity which causes the structure torsion effect is obvious, so the first 3 vibration mode contain torsion frequency in some certain of different degrees. The first model is X-major (where translational components in $\mathrm{X}$ orientation accounted for $76 \%$ ), the second model is torsion-major (where torsional component accounted for $65 \%$ ), and the third model is $\mathrm{Y}$ major (where translational components in $\mathrm{Y}$ orientation accounted for $88 \%$ ). The results of the first three modes of the model are shown in Fig .5 (b) - (d).

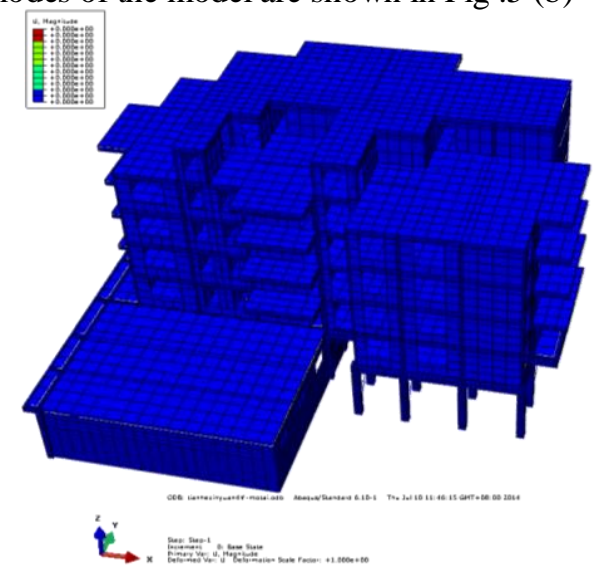

(a). The whole building. 


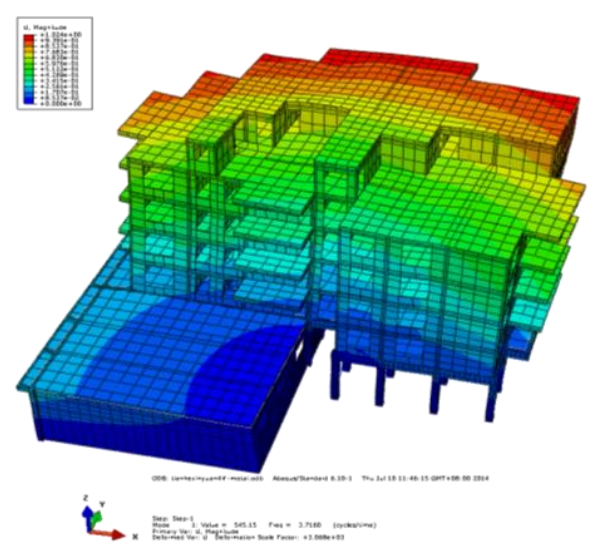

(b). The first order mode.

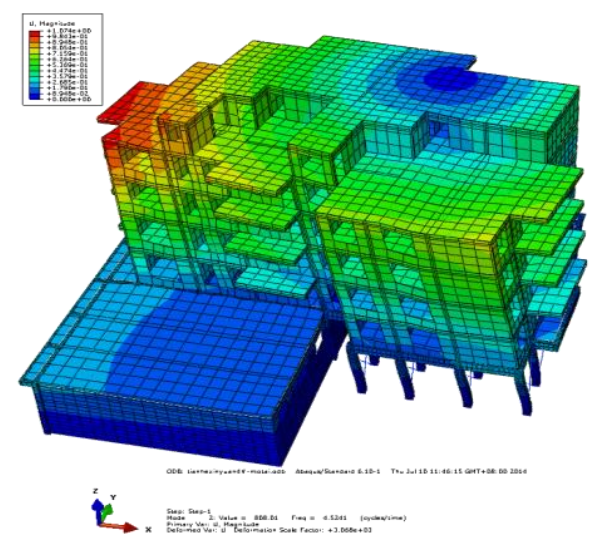

(c). The second order mode.

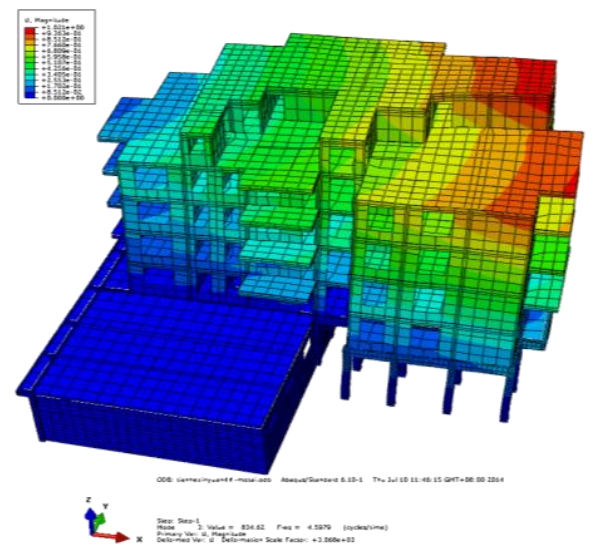

(d). The third order mode.

Figure 5. Finite element model and modal calculation results

The torsional period ratio of bottom frame structure is according to the literature [10]. The results show that the ratio of the first natural period of vibration in torsion-major and the first natural period of vibration in translationalmajor is 0.82 , meets the provisions of literature[10] which requires the ratio is no more than 0.9. But the actual earthquake damage shows that the torsion effect of structural was obvious and still severely damaged in Wenchuan earthquake. The main reason is that the stiffness of the first layer is concentrated in the reinforced concrete shear wall of the central staircase, and the lack of lateral load resisting member in the periphery and the corner of the structure in the first layer plane of structure will cause the torsional stiffness insufficient, which leads to the first natural period of vibration in torsion-major and translational-major is close and the torsional response of of the first layer is larger, eventually causing serious damage.

Thus it may be concluded that: (1) Torsional period ratio will not afford to control the torsional response when the eccentricity is large in irregular structure plane, and can also cause serious damage even the calculation meets requirements . (2) The structure should be designed with homogeneous distribution of stiffness, and the stiffness in the center position should be decreased. At the same time, lateral load resisting member should be set in the periphery of the structure, appropriately increase the floor torsional rigidity, and reduce the value of natural period of vibration in translational-major. (3) The torsional period ratio in literature [10] is used in tall buildings, but it is also necessary to limit the torsional period ratio in bottom frame structure, the ratio of the first natural period of vibration in torsion-major and the first natural period of vibration in translational-major should not be too close, and the torsion coupling reaction which will aggravate the damage should be avoided.

\section{ANALYSIS OF ELASTIC TIME-HISTORY}

\section{A. Selection of earthquake wave}

This paper used Wolong earthquake wave which was recorded in the Wenchuan earthquake as an external ground motion input. The effective duration time of the original Wolong wave was 140s, the peak acceleration of EW orientation was $957.7 \mathrm{gal}$, predominant frequency was $2.32 \mathrm{~Hz}$, the peak acceleration of NS orientation was $652.85 \mathrm{gal}$, and predominant frequency was $5.47 \mathrm{~Hz}$. In numerical calculation, in order to save the computational cost, seismic wave of $12 \mathrm{~s}$ were intercepted from the original wave to simulate the seismic process. The interception of Wolong earthquake waves contained the maximum peak acceleration both in EW and NS orientation, and ensured that the spectrum characteristics of the wave stayed the same. The acceleration time history of $12 \mathrm{~s}$ Wolong earthquake waves after interception and response spectrum curve were shown in Figure 6.

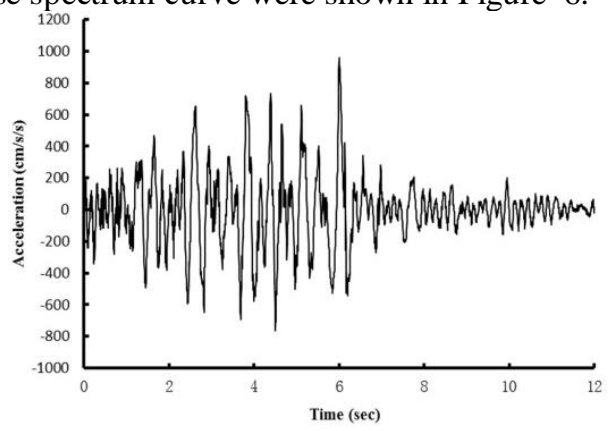

(a). EW orientation. 


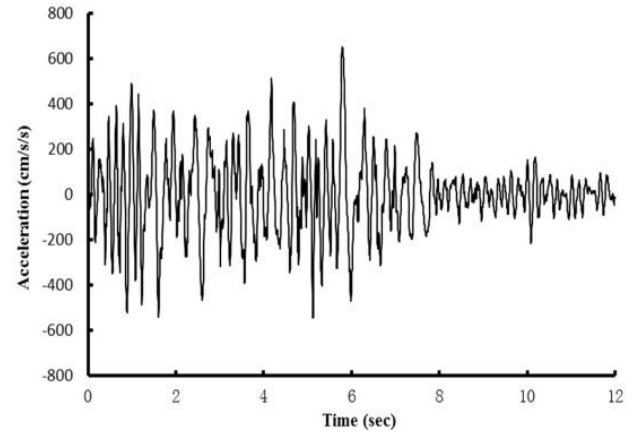

(b). NS orientation.

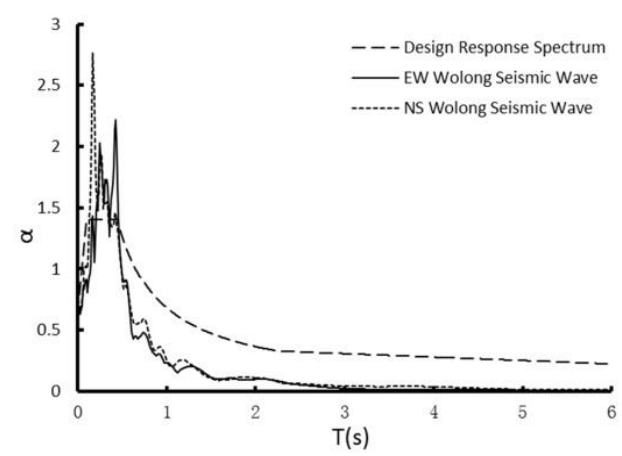

(c). Response spectrum.

Figure 6. Acceleration time-history data and response spectrum of Wolong earthquake waves after interception.

\section{B. The inter-story displacement angle}

The project adopts $\mathrm{X}, \mathrm{Y}$ bidirectional input Wolong earthquake waves on structural for elastic time-history analysis, adjust the input peak acceleration is $0.1 \mathrm{~g}$, the EW orientation of Wolong wave is input into the $\mathrm{X}$ direction and the NS orientation of Wolong wave is input into the Y direction. The calculation results of elastic inter-story displacement angle are shown in Fig .7. The maximum values of elastic inter-story displacement angle in both $\mathrm{X}$ and Yorientation is in the third layer. The maximum does not exceed $1 / 1300$ in the two directions, the structure is still in elastic stage, at the same time the structure is safe. The inter-story displacement angle in $\mathrm{X}$ orientation is larger than $\mathrm{Y}$ orientation, which is due to the structure has more loadbearing cross wall and large rigidity. While the longitudinal wall of structure has more doors and windows in $\mathrm{X}$ orientation, the stiffness is decreased, so the interstory displacement angle is larger than the Y orientation. The calculation result is reasonable when it is compared with the actual situation.

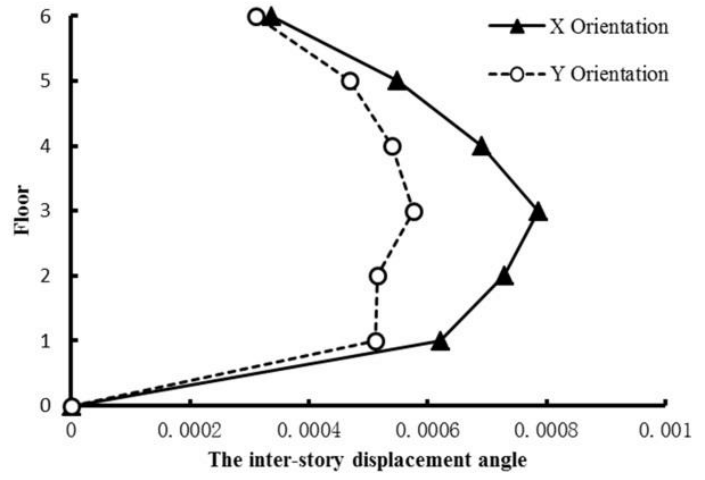

Figure 7. Elastic inter-story displacement angle.

\section{Torsional displacement ratio}

The torsional displacement ratio is defined as the ratio of the largest elastic horizontal displacement and average story displacement .The torsional displacement ratio is mainly used to limit irregular layout of structure plane, and to avoid excessive torsion effect caused by eccentric. Literature [7] points out that when the torsion displacement ratio is greater than 1.2 , it is belong to the irregular structure, and the provisions of this value should not be greater than 1.5. The calculation results of elastic response under $0.1 \mathrm{~g}$ are shown in Fig .8.

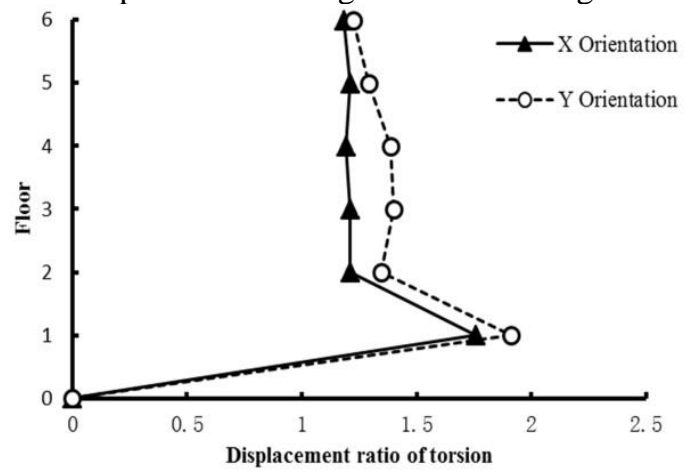

Figure 8. Torsional displacement ratio.

\section{CONCLUSIONS}

The main reason for the serious damage of structure is significant torsion effect under the horizontal earthquake action. First of all, the plane of the structure floor is irregular which has local large bay, leading to a larger eccentricity in the same floor between the center of mass and the center of stiffness. Secondly, the first floor layout of the structure is unreasonable, the stiffness of the first layer is concentrated in the reinforced concrete shear wall of the central staircase, and the lack of lateral load resisting member in the periphery and the corner of the structure in the first layer plane of structure will cause the torsional stiffness insufficient. By the impact of the torsional response of the first floor slab, the second masonry floor is seriously damage, and leading to serious damage of the overall structural eventually.

It is also necessary to limit the torsional period ratio in bottom frame structure, the ratio of the first natural period of vibration in torsion-major and the first natural period of vibration in translational-major should not be too close, and the torsion coupling reaction which will 
aggravate the damage should be avoided. The reduction of the vibration period of structure in torsion-major is achieved by increasing the torsional rigidity of the floors.

The design of structure lateral stiffness ratio is not reasonable. Too much reinforced concrete shear wall and infilled wall are set in the first layer, in addition to brick masonry podium. These components greatly increase the stiffness and shear bearing capacity of the underlying structure. And that makes the weak floor of the structure transfers from the bottom layer with better ductility and energy dissipation to the second layer of masonry floor. It is also the reason of the actual damage in the underlying structure of slight damage, and the second layer is destroyed. Proposed in the design, seismic joint should be set between the main structure and masonry podium, stiffness calculation includes only the stiffness of the main elements of the structure and no longer included in the stiffness of brick masonry podium. This design method is more reasonable to the system structure. In addition, this method of neglecting the contribution of the infilled wall is not always conservative. It is recommended in the design that the rigidity of the infilled wall and its shear bearing capacity should be included in.

\section{REFERENCES}

[1] B. T. Sun, P. L. Yan, C. F. Hu and M. Y. Zhang, "Overview on seismic damage to different structures in Yingxiu Town during Wenchuan Earthquake," Journal of Earthquake Engineering and Engineering Vibration, vol. 28(5), 2008, pp. 1-9.

[2] J. Q. Lin, Y. S. Chen and J Wang, "Analysis of seismic damage to highway bridges in Mianzhu City during Wenchuan Ms 8.0 earthquake," World Earthquake Engineering, vol. 26(1), 2010, pp. 80-85.

[3] GB 50011-2010. "Code for seismic design of buildings," China Architecture \& Building Press, Beijing, 2010.

[4] JGJ 248-2012. "Technical specification for earthquake resistant of masonry buildings with frame and seismic wall in the lower stories," China Architecture \& Building Press, Beijing, 2012.

[5] J. F. Huang, P. F. Xu, "Concept and algorithm of load-correlating center of rigidity of building structure," Journal of Building Structures, vol. 35(4), 2014, pp. 162-168.

[6] Y. H. Ma, W. G. Liu and W. F. He, "Influence analysis of different eccentricity ratio to seismic response of isolated irregular high-rise building," Earthquake Resistant Engineering and Retrofitting, vol. 33(5), 2011, pp. 1-6.

[7] GB 50010-2010. "Code for design of concrete structures," China Architecture \& Building Press, Beijing, 2010.

[8] GB 50003-2011. "Code for design of masonry structures," China Architecture \& Building Press, Beijing, 2011.

[9] GB 50023-2009. "Standard for seismic appraisal of buildings," China Architecture \& Building Press, Beijing, 2009.

[10] JGJ 3-2010. "Technical specification for concrete structures of tall building," China Architecture \& Building Press, Beijing: 2010. 